\title{
Considerações acerca do Neoliberalismo e do Progressismo na América Latina
}

Recebido: 31-03-2019

Aprovado: 21-05-2019

Jales Dantas da Costa ${ }^{1}$ Wolney de Carvalho ${ }^{2}$

\section{Introdução}

Os debates sobre o neoliberalismo, o progressismo e a situação latino-americana contemporânea voltam com toda força e validade, especialmente porque na primeira década do século XXI pairava a percepção de que uma guinada à esquerda estava se processando com efetividade em importantes Estados-nacionais, e que a América Latina se via frente à possibilidade de superar o neoliberalismo. Nesse momento histórico, sabe-se que isso não se concretizou, porque o neoliberalismo, longe de ser superado, está enraizado há quase cinco décadas no subcontinente e é uma etapa ${ }^{3}$ do capitalismo dependente contemporâneo.

Para Perry Anderson (2002), o nascimento do neoliberalismo se deu no pós-guerra na Europa Ocidental e na América do Norte. Suas origens e evolução marcam uma veemente reação teórica e política contra o intervencionismo estatal e o Welfare State. A reação teórica veio com a publicação em 1944 do livro "The Road to Serfdom" do austríaco Friedrich Hayek. A obra

\footnotetext{
${ }^{1}$ Jales Dantas da Costa é brasileiro, doutor em Ciências Sociais pelo Centro de Pesquisa e Pós-Graduação sobre as Américas (CEPPAC, UnB). Mestre e Graduado em Economia pelo Departamento de Economia da Universidade Federal de Santa Catarina (UFSC). Professor adjunto no Departamento de Economia e no Programa de Pósgraduação em Economia da Universidade de Brasília. Líder do Grupo de Pesquisa Revoluções e Contrarrevoluções (CNPq). Autor da tese "Brasil e Chile: riquezas e pobrezas". Organizador do livro "Capitalismo Histórico e Alternativas”.jalesdc@gmail.com

${ }^{2}$ Wolney de Carvalho é brasileiro, doutor em Sociologia Política pela Universidade Federal de Santa Catarina (UFSC). Mestre e Graduado em Economia pelo Departamento de Economia da UFSC. Professor Adjunto no curso de Ciências Econômicas e do Mestrado em Integração Contemporânea da América Latina (ICAL) na Universidade Federal da Integração Latino-Americana (UNILA). Autor de "As possibilidades do desenvolvimento econômico num país de capitalismo dependente". In: CRUZ, Clara Augustina Suárez et al (Org.). América Latina: olhares e perspectivas. Florianópolis: Editora Insular, 2016, 2a Ed, p. 331-347. wolneyc@ @otmail.com

${ }^{3}$ Duménil e Lévy destacam isso muito bem no texto "Una teoria marxista del neoliberalismo", mostrando que o neoliberalismo corresponde historicamente à segunda hegemonia da Finança. Ademais, demonstram como se prolifera uma nova organização social da produção, onde os diretores executivos ou altos executivos passam a assumir as funções outrora desempenhadas pelo capitalista ativo.
}

Revista de Estudos e Pesquisas sobre as Américas V.13 N.2 2019 ISSN: 1984-1639 
representa nada menos do que o "estatuto fundador do neoliberalismo" no qual Hayek expôs "um ataque apaixonado contra qualquer limitação do livre funcionamento dos mecanismos do mercado por parte do Estado" (2002, p.17).

O rápido crescimento da economia mundial durante a "era de ouro" do capitalismo deu pouca credibilidade para as advertências dos neoliberais contra os perigos representados pelo "keynesianismo e solidarismo reinantes". (HOBSBAWM, 2001; ANDERSON, 1995). É a partir de 1974-1975 que as ideias neoliberais ganham força com a grande crise do modelo econômico do pós-guerra, que atinge a totalidade dos países capitalistas desenvolvidos, levando-os a profunda recessão e inaugurando o novo fenômeno da stagflation (baixo crescimento com alta inflação).

Depois da experiência dos países da OCDE, o leste europeu foi a segunda região a aplicar o programa neoliberal ${ }^{4}$. Só mais tarde viria atingir a região da América Latina. Para o Conselho Latino Americano de Ciências Sociais (CLACSO) e o Centro Tricontinental (CETRI),

o neoliberalismo implantou-se rapidamente, principalmente sob a influência das organizações financeiras internacionais (FMI, Banco Mundial) que impuseram suas condições de crédito (entre outras os planos de ajuste estrutural), exigindo o rigor das políticas monetárias, a redução das funções do Estado por meio das privatizações e a diminuição de suas despesas, o pagamento regular do serviço da dívida... Tudo isso correspondia à política mundial de restabelecimento da taxa de acumulação do capital. (AMIN \& HOUTART, 2003, p.153).

Para realizar o projeto neoliberal seus artífices propuseram um conjunto articulado de cinco reformas estruturais no ordenamento sóciopolítico, com objetivo de instaurar uma sociedade assentada sob uma economia de mercado: a) implantar a retirada do Estado na esfera econômica, diminuindo o gasto público na criação de riqueza social; b) estabelecer a preeminência do capital privado no âmbito produtivo; c) impor a total abertura externa comercial e financeira; d) desenvolver a reforma do mercado de capitais eliminando as barreiras à livre circulação do mesmo; e) estabelecer um mercado de trabalho "livre", permitindo a contratação flexível do trabalhador. (ROSEMANN, 2006).

\footnotetext{
${ }^{4}$ Para François Houtart, "o neoliberalismo nada mais é do que a nova estratégia do capital para recuperar sua capacidade de acumulação, consecutiva à diminuição relativa da produtividade que conduziu ao esgotamento do modelo keynesiano e às novas possibilidades de que ele passa a dispor para recolonizar as economias periféricas" (2001, p.91).
}

Revista de Estudos e Pesquisas sobre as Américas V.13 N.2 2019 ISSN: 1984-1639 
O Chile produziu a primeira experiência neoliberal no mundo, pouco depois do golpe promovido pelo general Augusto Pinnochet no Chile em 11 de setembro de 1973. As "reformas" aplicadas na Bolívia (depois de 1985) representam outra "experiência-piloto" do neoliberalismo na região. Mas essas foram experiências isoladas até fins dos anos 1980. Foi somente com a chegada em 1988 de Carlos Salinas de Gortari à Presidência no México 5 que ocorre a virada para um neoliberalismo latino-americano. Ela se prolonga em 1989 com a vitória de Carlos Menem na Argentina e a reeleição de Carlos Andrés Perez na Venezuela, e em 1990 com a eleição de Alberto Fujimori no Peru. A versão brasileira do neoliberalismo, que deu os primeiros passos no final da década de 1980 ainda no governo de José Sarney, foi particularmente diferente dos outros países da região, isto porque no Brasil o neoliberalismo além de não poder contar com soluções de força, ainda teve de enfrentar uma forte burguesia industrial ${ }^{6}$ protegida pelo Estado e uma forte resistência do movimento social e político de esquerda. No Chile e Argentina, o neoliberalismo conseguiu se impor muito mais cedo, resultando na derrota da esquerda e do movimento popular nestes países. (ANDERSON, 1995; OLIVEIRA, 1995; SADER, 1995).

Note-se que no caso brasileiro, o avanço neoliberal tomou a ofensiva no governo Fernando Collor de Melo, mas não sem resistência da sociedade civil por meio de suas organizações mais potentes. Durante a primeira parte do governo Itamar, “a função pedagógica perversa da hiperinflação foi administrada a conta-gotas (...) precisamente para produzir o terreno fértil no qual se joga a semente neoliberal e ela progride" (OLIVEIRA, 1995, p.26). E progrediu durante os dois governos de Fernando Henrique Cardoso (1995-2002), e para perplexidade e frustração de muitos (e o alívio de outros poucos) prosseguiu em alguns de seus aspectos essenciais nas políticas econômicas adotadas nos governos Luiz Inácio Lula da Silva (2003-2010) e Dilma Rousseff (2011-2016), e aprofundando-se desmesuradamente durante o governo

\footnotetext{
${ }^{5}$ Cabe registrar que o governo De La Madri (eleito Presidente em 1982) não só abriu o México à economia global ao torná-lo signatário do Acordo Geral de Tarifas e Comércio (GATT) como implacou um programa de austeridade, bem como posteriormente recorreu à venda de empresas públicas e sufocou as batalhas trabalhistas. Não há assim consenso na literatura que aponte a introdução do neoliberalismo no México apenas com o governo Salinas. David Harvey, para citar apenas um estudioso do "mapa dos movimentos da neoliberalização", argumenta que o "programa de desenvolvimento econômico [De La Madri] foi formulado numa linguagem bem próxima da ortodoxia neoliberal" (2008, p.110).

${ }^{6}$ Referimo-nos a forte burgueia industrial brasileira quando comparada às demais burgueias industriais na região, já que as burguesias industriais dependendes são relativamente fracas quando comparadas às burguesias centrais.
}

Revista de Estudos e Pesquisas sobre as Américas V.13 N.2 2019 ISSN: 1984-1639 
ilegítimo de Michel Temer após o golpe de 2016, e segue atualmente (maio de 2019) implacando uma agenda ultraneoliberal no governo de Jair Bolsonaro.

O enfraquecimento econômico entre 1980 e 2003 parece ter contribuído para ter tornado ainda mais concentrada a renda e a riqueza no Brasil. ${ }^{7} \mathrm{O}$ abandono do projeto de industrialização nacional e o retorno ao modelo primário-exportador de matérias-primas e produtos agropecuários, foi acompanhado do avanço do ciclo da financeirização da riqueza no país. Um dos reflexos desta mudança, conforme destaca Pochmann (2004), foi a queda da participação da renda do trabalho na composição da renda nacional, que caiu quase $12 \%$ do final da década de 1970 ao início do século XXI. Nesse mesmo período, as políticas sociais no enfrentamento destes males foram muito tímidas. Para Vieira (2000) elas simplesmente inexistiram nos anos 1990.

Em todos os casos, as reformas neoliberais se destacaram ao longo do tempo na América Latina pela baixo crescimento econômico, desindustrialização das economias, exclusão social, expansão da pobreza, concentração de renda, geração de enormes déficits públicos, redução salarial, precarização das relações de trabalho, aumento do desemprego, deterioração dos serviços públicos, ampliação do setor informal de trabalho, expropriação de direitos fundamentais da maioria da população, redução da cidadania, enfraquecimento dos sindicatos, falência de pequenas empresas, expansão da violência e forte instabilidade política.

\footnotetext{
${ }^{7}$ A mediocridade nas taxas de crescimento do período "neoliberal" (de Collor em diante) era evidente diante da constatação de que o padrão de crescimento econômico durante a crise do desenvolvimentismo (fins dos anos 1980) tornara-se o padrão normal dos anos posteriores. Eis alguns dados comparativos reproduzidos por Francisco de Oliveira: "Em média, o crescimento do PIB mal alcançou os 2\% ao ano de 1990 a 2005 (taxa média de 2,06\%), resultado pior do que o dos três últimos anos do ciclo desenvolvimentista, encerrado com José Sarney em 1989. Naqueles anos, em meio à crise aberta pela débâcle do Cruzado e à conturbação da questão inflacionária, o crescimento médio ficou em 2,2\%". (Oliveira, 2006, p.226). Ao passo que os trabalhadores viram minguar a sua participação na renda nacional ao longo dos anos 1980-2000, de 50\% e 37\%. O índice do poder de compra do salário mínimo despencou no período, ao passo que os mais ricos ficaram ainda mais ricos. A relação da apropriação da renda nacional entre o topo da pirâmide e sua base (10\% + ricos/40\% + pobres) subiu de 20,3 e para 21,2 no período. (Campos, Pochmann et al, 2004, p.38-39). Em Os ricos no Brasil, Pochmann e outros apresentaram dados relevantes sobre a riqueza dos "do tope". A conclusão é surpreendetemente perturbadora quanto à permanência secular de elevadíssmo grau de desigualdade, de apropriação contínua de enorme fatia da renda nacional e detenção de extraordinário patrimônio nas mãos de pouquíssmas famílias quando comparadas ao conjunto das famílias residentes no país. Para fins do período que estamos analisando, destacamos o dado que "entre 1995 e 2004 (...) a renda do trabalho perdeu $9 \%$ de seu peso relativo na renda nacional, ao passo que a renda da propriedade cresceu $12,3 \%$ " (Pochmann, 2012, p.09).
}

Revista de Estudos e Pesquisas sobre as Américas V.13 N.2 2019 ISSN: 1984-1639 


\section{O neoliberalismo latino-americano e a ratificação do capitalismo dependente}

O neoliberalismo na América Latina é concomitante ao quarto ${ }^{8}$ padrão de dominação externa (FERNANDES, 2009). Este novo padrão de dominação é resultado histórico da própria inserção latino-americana na estrutura do sistema capitalista desde 1492, mas nos anos 1970 se expressa como o controle interno das economias dependentes pelos interesses externos. É o que se denomina também como fase de imperialismo total, pois os interesses do capital financeiro internacional operam em todos os níveis a partir de dentro das nações latino-americanas: na esfera produtiva, comercial e na esfera financeira. A partir de então, as principais indústrias em funcionamento nas três esferas acima destacadas, conformam-se como espaços de atuação de grandes sociedades anônimas. Essas unidades de negócios, através dos movimentos de concentração e centralização característicos do capitalismo já destacados por Marx (2008), pouco a pouco transformaram as principais indústrias latino-americanas em espaços de atuação de grandes oligopólios e monopólios, pois:

Uma superpotência capitalista necessita de tipos diferentes de mercados externos, desde as economias capitalistas avançadas até economias dependentes, semicoloniais e coloniais. A preservação de sua posição depende de vigilância e controle contínuos de expansão das grandes empresas corporativas, e da intensificação crescente das relações econômicas com os mercados externos. Assim, uma superpotência capitalista não pode enfrentar e resolver nem os problemas de

\footnotetext{
${ }^{8}$ Vale destacar que para Fernandes (2009), Brasil, Uruguai, Argentina, México e Chile passaram por quatro padrões de dominação externa. O primeiro deles esteve a cargo de Portugual e Espanha, o chamado "antigo sistema colonial" que durou aproximadamente três séculos. O segundo padrão de dominação externo surgiu da desintegração do antigo sistema colonial: o neocolonialismo. Teve à sua frente a Inglaterra, a qual controlou posições estratégicas nas esferas comerciais e financeiras entre 1800-1850. O terceiro padrão de dominação externo é aquele em que as influências externas atingiram todas as esferas da economia, sociedade e cultura. A dominação externa torna-se imperialista segundo o autor, pois incorpora de forma direta algumas fases do processo de crescimento e desenvolvimento econômico. Mas esse imperialismo é restrito, pois a dominação se dá em alguns setores e opera acima tudo desde o exterior. Entende-se que o capitalismo dependente tem suas origens exatamente entre o segundo e o terceiro padrão de dominação externa, momento da independência política dos Estados nacionais e do surgimento dos cidadãos latino-americanos. Veja-se que esse período marca primeiramente, o início da implantação sobretudo do liberalismo político latino-americano com o predomino das oligarquias na condução do processo liberador da região; em segundo, é característico desse tempo histórico uma a acumulação originária de capital insuficiente para a futura implantação da reprodução especificamente capitalista na América Latina, a qual se iniciará nas trêss primeiras décadas do século XXX. era insuficiente, em especial porque as jovens nações apenas a algumas décadas acumulavam capitais enquanto propriedade de capitalistas latino-amercianos, sobretudo nos setores voltados à produção de produtos primários demandados pelo mercado nacional e coordenados em geral pela Inglaterra, mas também por França, Alemanha e posteriormente EUA, que controlavam os principais empreendimentos no setor comercial e financeiro., , onde o o formato da reprodução sistema de trabalho agroexportaçãonão haviam acumulado o qual foi acampanhado
}

Revista de Estudos e Pesquisas sobre as Américas V.13 N.2 2019 ISSN: 1984-1639 
seus parceiros menores, nem muito menos os problemas das economias dependentes, semicoloniais ou coloniais, incorporadas ao seu espaço econômico, sociocultural e político. (FERNANDES, 2009, p.36)

Como se viu anteriormente, o quarto padrão de dominação externa se estabelece juntamente com o neoliberalismo, e ambos ratificam o desenvolvimento do capitalismo dependente e associado na América Latina nos anos 1970. É crescente a concentração e centralização dos capitais nos setores/indústrias mais importantes no subcontinente depois dos anos 1970. Isso ocorreu sob a condução dos grandes oligopólios e monopólios industriais nacionais e (ou) estrangeiros - associados com os grandes bancos - nacionais e (ou) estrangeiros - dando origem ao que Lênin (1985) denominara de capital financeiro. Assim, se o capitalismo dependente surge no final do século XIX/início do século XX por faltar às burguesias nacionais latino-americanas os capitais necessários ao desenvolvimento de um capitalismo autônomo ${ }^{9}$, nos anos 1970 esse capitalismo dependente se ratifica através da associação do capital financeiro latino-americano ao capital financeiro internacional. Note-se que Lênin demonstrara no início do século XX como o imperialismo é a política do capital financeiro, o que permite identificar como o princípio do neoliberalismo na América Latina é o momento histórico do que Florestan denominou de moderno imperialismo:

\footnotetext{
${ }^{9}$ Entende-se por capitalismo autônomo a produção e reprodução do capital posta a cabo predominantemente por capitalistas da região ou Estados-nações em questão, no caso da América Latina. Para que isso se concretizasse, os cidadãos das jovens nações latino-americanas do século XIX deveriam ter efetuado uma acumulação primitiva, a qual os capacitaria a iniciar o empreendimento capitalista nos mais diversos setores econômicos, em especial os mais importantes - e a dominá-los. Mas, diferentemente dos Estados-nações do centro do capitalismo, na América Latina essa acumulação primitiva foi insuficiente, e ademais, os latino-americanos após os processos de independência, se ocuparam em geral da produção de matérias primas, enquanto os capitais forâneos - desde cedo os capitais ingleses e depois os alemães, estadunidenses, franceses... - controlavam o comércio exterior e os serviços financeiros. Essa dependência de capitais externos se aprofunda e se intensifica ainda mais, na medida em que as próprias elites burguesas desses jovens Estados se associam aos capitais estrangeiros para também atuarem em setores econômicos importantes no início do século XX, assim como, quando os Estados nacionais, para fazerem frente à infraestrutura necessária ao desenvolvimento capitalista se financiam através do endividamento público externo. Finalmente, há que se destacar que para implantação de um capitalismo autônomo se faz necessário um Estado liberal/burguês ente político - forte. Isso por sua vez irá se refletir na estrutura hierárquica do capitalismo mundial, a qual tendo em sua base a divisão internacional do trabalho ratificará o status de cada país na mesma. Ora, os Estados nacionais da América Latina não tinham apenas uma estrutura orçamentária limitada, reflexo do próprio grau de desenvolvimento capitalista nesse então, mas a própria revolução burguesa fora um empreendimento apenas das elites crioulas/oligárquicas, pouco contribuindo para a garantia das liberdades, da democracia e dos direitos da maioria da população. Isso também se materializou no surgimento de uma força de trabalho pouco qualificada, e por sua vez inserida num mercado capitalista onde a superexploração já se manifestava como uma das características dos países de capitalismo dependente.
}

Revista de Estudos e Pesquisas sobre as Américas V.13 N.2 2019 ISSN: 1984-1639 
A erupção do moderno imperialismo iniciou-se suavemente, através de empresas corporativas norte-americanas ou europeias, que pareciam corresponder aos padrões ou às aspirações de crescimento nacional autosustentado, conscientemente almejado pelas burguesias latino-americanas e suas elites no poder ou pelos governos. Por isso, eslas foram saudadas como uma contribuição efetiva para o "desarrolismo" ou o "desenvolvimentismo", recebendo apoio econômico e político irracional. (...). As empresas anteriores, moldadas para um mercado competitivo restrito, foram absorvidas ou destruídas, as estruturas econômicas existentes foram adaptadas às dimensões e às funções das empresas corporativas, as bases para o crescimento econômico autônomo e a integração nacional da economia, conquistadas tão arduamente, foram postas a serviço dessas empresas e dos seus poderosos interesses privados.

O processo como um todo não é um fenômeno norte-americano. No entanto, os Estados Unidos desempenharam o papel pioneiro e dominante. Outras nações, especialmente europeias (como a Alemanha, a França, a Inglaterra etc.) e o Japão, tomaram parte nesse processo lucrativo de recolonialismo. (FERNANDES, 2009, p. 31).

Nessa direção, os Estados da região latino-americana foram em graus distintos debilitados no enfrentamento dos monopólios, das transnacionais, e das frações mais concentradas do capital; na dificuldade de introduzir ou sustentar regulamentações nos mercados; na adoção de políticas que garantissem o fornecimento de bens públicos; na impossibilidade de romper com as políticas de "ajuste estrutural" recomendadas por instituições internacionais (Banco Mundial, Fundo Monetário Internacional e outras agências internacionais) que terminaram na reconcentração de renda, congelamento de salários, na privatização de empresas, serviços públicos e na falência do sistema de seguridade social.

Quase todas as pretensões de políticas ortodoxas neoliberais objetivaram ampliar o grau de abertura da economia a fim de alcançar um maior grau de competitividade de suas atividades produtivas; racionalizar a participação do Estado na economia, isto é, liberalizar os mercados, os preços e as atividades produtivas; e estabilizar o comportamento dos preços e de outras variáveis macroeconômicas em economias que têm estado submetidas a fortes processos inflacionários. Observa-se, no entanto, que diversos casos de retorno à ortodoxia, como os do Chile, México, Argentina e Brasil, apresentaram importantes diferenças ao lado de similitudes. A implantação de elementos de políticas econômicas de caráter ortodoxo se deu por meio de diferentes formas e graus variados de intensidade, e o modo pelo qual a situação e a política sociais foram afetadas por essas medidas, também se diferenciou em cada um dos países estudados. Tal diferenciação ocorreu pela natureza, extensão e intensidade das medidas de ajuste econômico, bem como pelas

Revista de Estudos e Pesquisas sobre as Américas V.13 N.2 2019 ISSN: 1984-1639 
características da situação social pré-existente e pela estruturação prévia do setor público, sobretudo do setor social. (SOARES, 2001).

Já nos anos 1980, no lugar do incipiente "Estado de Bem-Estar" existente na região, restou um "Estado de Mal-Estar" segundo Soares (2001). O novo discurso ideológico (logo dominante) passara a ser atacar a ineficiência do Estado. Estabeleceu-se a chamada década perdida: o PIB per capita anual médio entre 1981-1990 (de)cresceu (-0,9\%) e entre 1991-1995 o percentual de crescimento foi de $0,8 \%$. A pobreza na região aumentou, passando de 63 milhões de pessoas em 1987 para 78 milhões em 1998. Segundo dados da CEPAL de $2017^{10}$, em 2014 se encontravam em situação de pobreza $28,5 \%$ da população latino-americana (168 milhões de pessoas), já em 2015 aumentara para 29,8\% (178 milhões de pessoas) e em 2016 o número de pobres atingira a cifra de 30,7\% da população da região (186 milhões de pessoas). O número de pessoas na faixa da pobreza absoluta representava 61 milhões de pessoas neste último ano analisado.

Ao longo das últimas décadas do século XX foi adotada na América Latina uma estratégia deliberada de reduzir a importância da atuação estatal em setores econômicos essenciais, reduzindo a presença do setor industrial e das soberanias nacionais. O PIB industrial latinoamericano, que representava $12,7 \%$ no período 1970-1974, decrescera para 6,4\% em 2002/2006. Houve importante alteração na participação econômica das principais 500 empresas latinoamericanas: enquanto as empresas estrangeiras ampliaram a sua participação, de $27 \%$ para $39 \%$ entre os anos de 1991 e 2001, as empresas estatais reduziram sua presença, de 20\% para 9\% no mesmo período. A economia da região vem sendo reconvertida em prol da agroexportação, da mineração e dos serviços em detrimento do desenvolvimento industrial, aprofundamento nossa dependência. (KATZ, 2016).

Constituíram-se burguesias mais associadas com empresas estrangeiras, consolidando um processo que começou nos anos 1960 no Brasil, continuou nos anos 1980 na Argentina e se consolidou no México nos anos 1990. Este setor deixou para trás seu início na indústria, e se estendeu à agromineração e aos serviços. (KATZ, 2016, p. 29)

\footnotetext{
10 Dados disponíveis em: https://www.cepal.org/pt-br/comunicados/pobreza-aumentou-2016-america-latinaalcancou-307-sua-populacao-porcentagem-que-se, acesso em 11/07/2018.
}

Revista de Estudos e Pesquisas sobre as Américas V.13 N.2 2019 ISSN: 1984-1639 
Apesar do avanço neoliberal na região nas últimas décadas, o próprio papel do Estado e as políticas de desenvolvimento na América Latina apresentaram distinções. Para Katz (2016), México, Colombia e Perú estiveram muito alinhados com as opções do desenvolvimento econômico neoliberal estadunidense, objetivando o aprofundamento dos acordos de livre comércio e livre mobilidade dos capitais, o que resultou no aprofundamento da extração mineral, no pequeno desenvolvimento dos parques industriais e na deterioração das condições laborais. Em se tratando de Brasil e Argentina, os governos mais progressistas de Lula e Kirchner após os anos 2003 conseguiram frear parcialmente a escalada neoliberal adotando políticas econômicas heterodoxas e uma maior ação estatal. Isso fortalecera, segundo o autor, as respectivas economias nacionais, seus mercados internos e a industria nacional, inclusive observou-se o aprofundamento da integração via Mercosul, sem no entanto, romper definitivamente com o neoliberalismo.

Finalmente, Venezuela e Bolívia visaram alternativas antiimperialistas ao propor um desenvolvimento econômico com redistribuição de renda, inclusão social e uma forte atuação estatal nos setores mineral e petrolífero.

\section{O impacto do neoliberalismo e do progressismo sobre a classe trabalhadora na América Latina contemporânea}

Como se destacou anteriormente, o neoliberalismo é uma etapa do capitalismo, e se na América Latina ao longo do período dos governos progressistas - iniciado em 1999 com Cháves na Venezuela - esse arrefeceu, após 2013 assiste-se a um recrudescimento do mesmo, com impactos significativos sobre a classe trabalhadora. Em primeiro plano, dado o avanço do capital financeiro nacional e internacional nos principais setores/indústrias, observa-se que a crescente centralização dos capitais se refletiu no crescente aumento da composição orgânica do capital relação estabelecida entre os dispêndios das unidades capitalistas com a compra dos meios de produção e a força de trabalho - no período do neoliberalismo, e a taxa geral de lucro manifestou com mais força sua queda tendencial. Isso ensejou a práxis de movimentos contratendenciais a esse resultado próprio do desenvolvimento histórico do capitalismo.

Assim, na medida em que cresceu a composição orgânica do capital, foi necessário aumentar o grau de exploração sobre a classe trabalhadora através do aumento da mais-valia

Revista de Estudos e Pesquisas sobre as Américas V.13 N.2 2019 ISSN: 1984-1639 
absoluta e relativa para compensar a queda na taxa de lucro. A primeira, permitiu com a própria introdução de máquinas e equipamentos mais elaborados nos processos produtivos, o aumento da intensidade do trabalho, e isso resultou no aumento do trabalho excedente apropriado pelas unidades capitalistas, mesmo mantendo-se a jornada de trabalho constante. Já a segunda, possibilitou através da maior produtividade do trabalho nos setores produtores dos meios de subsistência - que compõem a cesta dos bens consumidos pelos trabalhadores -, a redução do valor pago para parcela da força de trabalho comprada pelas unidades capitalistas, e nesse sentido, verifica-se também um aumento do trabalho excedente apropriado por essas unidades, na medida em que o trabalho necessário à reprodução da força de trabalho diminuiu. Ademais, uma prática muito comum na região latino-americana tem sido o aumento dos lucros através do pagamento de um salário aos trabalhadores abaixo do valor efetivo do custo de reprodução da força de trabalho - o que alguns autores ${ }^{11}$ chamam de superexploração.

Portanto, observa-se que no neoliberalismo aumentou o grau de exploração dos trabalhadores pelas três vias acima indicadas, e isso, para além de compensar a queda na taxa global de lucros, permitiu e permite também ao capital financeiro nacional e internacional operante na região, qualificar-se na concorrência do mercado mundial, pois parte desse acréscimo de mais-valia acumulado pelas vias acima indicadas, poderá ser utilizado para venderem-se as mercadorias nesse mercado, abaixo dos seus valores, o que em última instância aparece como um aumento da competitividade empresarial latino-americana no comércio internacional.

Outra questão a ser destacada, e que está atrelada ao aumento da composição orgânica do capital, é o aumento do exército industrial de reserva. Marx (2008) permite verificar como o desenvolvimento histórico do capitalismo traz em seu seio o próprio desenvolvimento das forças produtivas - a exemplo da força produtiva do trabalho; o próprio trabalho objetivado que se manifesta nos meios de produção como capital fixo e capital constante; e a própria ciência -, e na medida em que se consolida a subsunção real do trabalho ao capital, uma massa crescente de trabalhadores é tornada obsoleta para as necessidades de reprodução desse capital e engrossa as

\footnotetext{
${ }^{11}$ Marx em "O Capital" coloca que nesse caso a reprodução da força de trabalho se dá de forma atrofiada e que "o trabalho excedente estaria aí prolongado com a violação de seus limites normais, usurpando parte do tempo de trabalho necessário" (MARX, 2008, L. 1 V I, 364, 365). Uma boa contribuição também é a de Marini em seu trabalho sobre a "dialética da dependência", onde discute a questão da superexploração na América Latina.
}

Revista de Estudos e Pesquisas sobre as Américas V.13 N.2 2019 ISSN: 1984-1639 
fileiras do exército industrial de reserva. Note-se que esses trabalhadores se defrontam com a impossibilidade de venderem a força de trabalho regularmente, e para sobreviverem terão de atuar no mercado informal ${ }^{12}$ de trabalho ou em atividades ilícitas. Para se ter uma ideia do cenário latino-americano atual, o Jornal do Brasil/Economia de maio de 2018, baseado nos relatórios da OIT, destaca que a cifra de informalidade na América Latina já atinge a casa dos 53\% da População Economicamente Ativa. Destaca ainda que no caso brasileiro - e com base nos estudos do PNAD de março de 2018 - apenas 36,3 \% (32 milhões) dos trabalhadores no setor privado tinham carteira de trabalho assinada (a População Economicamente Ativa é de aproximadamente 91 milhões de trabalhadores).

Desse modo e conforme o exposto anteriormente, não surpreende que trabalhadores latino-americanos se defrontem nas últimas cinco décadas - período neoliberal e progressista com o aumento no grau de exploração enquanto necessidade do reestabelecimento das taxas de lucro do capital financeiro nacional e internacional, operantes na região. Ademais, a crescente subsunção real do trabalho ao capital que se verifica nos principais setores da indústria, comércio e serviços - espaços onde opera esse capital financeiro - transmuta-se em uma crescente informalidade no mercado de trabalho.

Por último, há que se observar ainda duas questões que visam aprofundar ainda mais a exploração da classe trabalhadora. A primeira diz respeito às reformas trabalhistas em curso na Latinoamérica. É que historicamente, as Cartas Magnas dos Estados nacionais têm demonstrado suas limitações no que trata às conquistas, garantias e direitos fundamentais dos homens, em especial dos trabalhadores. Isso ocorre porque o desenvolvimento histórico do capitalismo

\footnotetext{
${ }^{12}$ Sobre essa discussão, Ricardo Antunes (2016) destaca que existem três tipos de modalidade de informalidade: a primeira modalidade diz respeito aos trabalhadores informais tradicionais. Nessa modalidade se encontram os "menos instáveis", os quais vivem da sua própria força de trabalho e se utilizam do auxílio do trabalho familiar para desenvolverem suas atividades, em geral voltadas para o setor de prestação de serviços como jardinagem, construção civil, costura, oficinas de reparos, sapataria, etc. Se encontram também nessa modalidade, os "mais instáveis" como carroceiros, carregadores, serviços de rua e que podem inclusive ser subempregados pelos "menos instáveis" acima. Por último, os trabalhadores "ocasionais" ou "temporários", que realizam atividades informais até voltarem a vender a força de trabalho regularmente. Uma segunda modalidade corresponde aos "trabalhadores informais assalariados sem registro", os quais vendem a vendem a força de trabalho sem carteira de trabalho assinada, como por exemplo em parte da indústria têxtil, de confecções e calçados. A terceira modalidade destacada pelo autor, são "os trabalhadores informais por conta própria", os quais também contam com auxílio de familiares e subcontratam força de trabalho assalariada. Entende-se que o importante a se verificar, é que todas essas formas de trabalho informal revelam-se frente à impossibilidade crescente da venda da força de trabalho com carteira assinada.
}

Revista de Estudos e Pesquisas sobre as Américas V.13 N.2 2019 ISSN: 1984-1639 
manifesta como uma contradição inerente na atualidade, a impossibilidade de cumprir as conquistas dos trabalhadores em especial no último século. Nesse sentido, é importante perceber que os benefícios/direitos trabalhistas conquistados significaram indiretamente custos maiores da força de trabalho, por isso mesmo, o neoliberalismo traz em seu bojo o anseio pela flexibilização desses custos laborais, o que significa outra forma de redução dos custos da força de trabalho, e por consequência, de reestabelecimento das taxas de lucro.

A segunda questão refere-se à reforma nos regimes previdenciários estatais. Aqui é importante perceber que a manutenção da estrutura previdenciária estatal dos Estados nacionais latino-americanos, via de regra, concorre com outros gastos ou alocações pecuniárias do orçamento estatal, a exemplo: a saúde, educação, saneamento e a dívida pública ${ }^{13}$. Sabe-se também que a maioria dos Estados nacionais passa por um crescente endividamento público ${ }^{14}$, o que acaba por se refletir num esforço maior de contenção dos gastos com as rubricas acima, exceto em se tratando dos dispêndios com a dívida. Desse modo, em geral os Estados da América Latina - em se observando o status do ente político -, encontram-se sob pressão do capital financeiro ${ }^{15}$ que é o grande detentor dos títulos da dívida pública e exige o pagamento regular dos serviços e amortizações dessa dívida, obrigando-os a reduzir os gastos com as demandas sociais,

\footnotetext{
${ }^{13}$ Extremamente elucidativo é o trabalho da Coordenação Nacional da Auditoria Cidadã da Dívida, elaborado no mês de maio de 2018, que avalia o orçamento federal do Brasil executado em 2017. Está muito claro que do total do orçamento federal, $39,7 \%$ fora destinado para o pagamento de juros e amortizações da dívida pública, enquanto que o gasto com a previdência social foi de $25,66 \%$ desse orçamento. Mas impactante ainda são os outros gastos quando comparados com as despesas com a dívida. Para a saúde pública brasileira o percentual gasto foi de apenas 4,14\%. No caso da educação o percentual destinado foi de $4,10 \%$ do orçamento, e o gasto com saneamento fora de míseros $0,03 \%$. Verifica-se assim facilmente, a discrepância na alocação dos recursos do Governo Federal e as prioridades do ente político. Disponível em https://auditoriacidada.org.br/wp-content/uploads/2018/05/Carta-Aberta-a-Populacaoversao-final.pdf

${ }^{14}$ Aqui é importante perceber que historicamente o endividamento público tem suas origens nas despesas extraordinárias do Estado, e grande parte dessas despesas foram e continuam estando relacionadas às demandas necessária para a própria reprodução capitalista, como por exemplo a criação de uma malha rodoviária e ferroviária, a abertura de canais e construção de grandes usinas, construção e modernização de portos e aeroportos. Raros são os casos na história do capitalismo em que a dívida pública fora efetuada para o atendimento das necessidades sociais da classe trabalhadora, como saúde e educação.

${ }^{15}$ Segundo o G1/Economia de 21/01/2018, a dívida pública interna do Estado brasileiro em 2017 era de 3,43 trilhões de $\mathrm{R}$ \$, e a dívida pública externa era de módicos 123,78 bilhões de reais. A propriedade dos títulos da dívida pública se concentrava da seguinte forma: 1) fundos de previdência com 874 bilhões de reais ou $25,4 \%$ do total; 2) já os fundos de investimento detinham 864,9 bi de reais ou $25,18 \%$ do total; 3 )as instituições financeiras por sua vez, com 766 bilhões de reais ou 22,3\% do total; 4)finalmente, investidores internacionais com 416 bilhões de reais ou 12,12\% do total. Constata-se assim como a dívida pública está concentrada acima de tudo nas mãos do grande capital financeiro nacional. Disponível em: https://g1.globo.com/economia/noticia/divida-publica-sobe-143-em-2017-para-r355-trilhoes-e-bate-recorde.ghtml
}

Revista de Estudos e Pesquisas sobre as Américas V.13 N.2 2019 ISSN: 1984-1639 
a exemplo o pagamento das aposentadorias.

Mas note-se que o crescente gasto público decorrente das altas taxas de juros pagas aos detentores da dívida pública poderia ser compensado pelo estabelecimento de uma carga tributária progressiva. Só que isso implicaria numa transferência maior de parte dos lucros das unidades capitalistas e das próprias fortunas pessoais ao Estado, com reflexos negativos em especial sobre as taxas de lucro. Por outro lado, esse crescente endividamento estatal ancorado em taxas de juros extorsivas, poderia passar por uma auditoria da dívida pública de forma a auditar os excessos tanto no montante dessa dívida como com relação aos juros pagos mensal ou anualmente. No entanto, isso teria reflexos negativos sobre a propriedade dos títulos públicos em poder do capital financeiro nacional e internacional, bem como resultaria numa redução dos juros auferidos por esse capital.

Por isso, longe de discutir uma reforma tributária progressiva e(ou) uma auditoria da dívida pública, os entes políticos latinoamericanos em geral, têm optado pelo aumento na idade para o direito à aposentadoria, associado à redução dos benefícios previdenciários dos futuros aposentados. Dessa maneira, o que se percebe é que na atualidade, para além da intensificação da exploração dos trabalhadores - característica do funcionamento do capitalismo em sua etapa neoliberal -, tem sido imputado à classe trabalhadora os sucessivos déficits estatais, supostamente originados por um regime de previdência demasiado paternalista, quando na realidade, busca-se a manutenção dos superprivilégios dos detentores do capital.

\section{A esquerda latino-americana frente ao avanço neoliberal: um precedente rico em lições para o século XXI}

As ditaduras militares e a implantação dos modelos neoliberais produziram uma mudança nas correlações de força entre as classes sociais, e a consolidação do capitalismo dependente na América Latina. Nenhum setor da esquerda deixou de ser afetado pela retomada da dominação dos Estados Unidos, bem como do esgotamento do ensaio para erigir um "Estado de bem-estar" a moda latino-americana e o retorno da hegemonia neoliberal, dentro e fora da região. Sader (2007) aponta que praticamente todos os movimentos armados tinham sido derrotados de forma repressiva por governos ditatoriais, e na década de 1990 muitos dos partidos de esquerda 
sofreram os impactos da desagregação da antiga URSS e da proposta do "socialismo real", adotando com isso uma reciclagem neoliberal:

O regime sandinista se havia esgotado e havia sido derrotado nas urnas em 1990. Os partidos comunistas - inclusive aqueles que haviam sido tradicionalmente os mais fortes, afora o cubano, os PCs do Chile e do Uruguai - foram reduzidos à impotência,enfraquecendo-se igualmente as centrais sindicais dirigidas ou hegemonizadas por eles. Alguns chegaram à mudança do nome e à sua descaracterização, como o caso do PC brasileiro. Tudo acontecendo de forma bastante paralela ao ocorrido com os PCs da Europa ocidental, demonstrando como o fim da União Soviética havia sido um fator decisivo nesse declínio. As organizações sindicais como um todo se debilitaram sob o impacto das políticas recessivas de ajuste fiscal, assim como as de "flexibilização laboral", que no seu conjunto promoveram a precariedade das relações de trabalho para a maioria dos trabalhadores do continente. Os partidos socialistas, socialdemocratas e os movimentos e partidos conhecidos como "populistas" e nacionalistas se reciclaram, de forma igualmente paralela ao fenômeno europeu, para políticas neoliberais. O peronismo, o PRI mexicano, o Partido Socialista Chileno, o PSDB no Brasil, a Ação Democrática na Venezuela, o MIR da Bolívia - são exemplos claros desse processo. Com isso, abandonaram suas tradicionais políticas de regulação estatal de distribuição de renda e tornaram-se responsáveis pela extensão do neoliberalismo ao conjunto do continente, abandonando o já debilitado campo da esquerda. (SADER, 2007, p.117-118)

A desagregação da URSS e do campo socialista e a consequente perda da referência histórica e ideológica foi um duro golpe para esquerda, sobretudo para os partidos comunistas, os quais deixaram de ser uma corrente com influência política no continente. À adesão progressiva de forças socialdemocratas e nacionalistas ao modelo neoliberal reforçou ainda mais este isolamento. Para o referido autor, a viabilidade do socialismo foi em muito questionada no seio da esquerda, e a ideologia neoliberal ${ }^{16}$ passou progressivamente a seduzir corações e mentes dos mais variados espectros ideológicos.

A extrema vulnerabilidade financeira das economias latino-americanas, fundamentalmente pelo peso de suas dívidas externas nos anos 1980, fez com que a hegemonia ideológica neoliberal assentasse definitivamente suas raízes no continente. Para Ha-Joon Chang (2004), a tese do "Estado mínimo", da adoção de "boas políticas" e "boas instituições" foram levados muito a sério na América Latina. As recomendações do Consenso de Washington foram

\footnotetext{
${ }^{16}$ A citação que se segue, bem detalha o que veio a ser a ideologia neoliberal ainda dominante: "A derrota do campo socialista em escala mundial foi seguida de um projeto ideológico que substitui o Estado pela empresa e pelo mercado, o cidadão pelo consumo, a regulação econômica pelo livre-comércio, os espaços públicos pelos shopping centers, o trabalhador pelo indivíduo, a ideologia pelo marketing, a palavra pela imagem, a escrita pela mídia visual e o livro pelo vídeo, as concentrações de rua pelas campanhas televisivas, os direitos pela competição, a novela escrita pela telenovela, os jornais pelo noticiário de televisão". (Sader, 2009, p.52)
}

Revista de Estudos e Pesquisas sobre as Américas V.13 N.2 2019 ISSN: 1984-1639 
aplicadas servilmente pelos governos desta região, mesmo por aqueles eleitos com o discurso de buscar alternativas de política econômica.

O mal-estar social provocado pelas reformas neoliberalizantes foi concomitante ao crescimento da agitação da resistência mundial contra os seus efeitos deletérios, sobretudo na América Latina, região que se tornou símbolo das convergências dos movimentos sociais. Organizações camponesas, indígenas, movimentos de mulheres, coletivos militantes, organizações não governamentais (ONGs), organizações sociais e juvenis chegaram a formar uma verdadeira "aliança global". Do I Encontro Intercontinental pela Humanidade e contra o Neoliberalismo, em Chiapas no México (1996), passando por Seattle (1999) ao diversos Fórum Social Mundial, um heterogêneo e amplo movimento que se organizou na forma de um “movimento antimundialização neoliberal”, na denominação de Seoane e Taddei (2001).

E não por acaso a esquerda passou a definir o seu campo na luta antineoliberal. Como resultado das profundas e regressivas conseqüências dessa "transição conservadora", em que cada vez mais grupos sociais eram afetados pelas políticas neoliberais, "novos movimentos sociais", tanto de base rural como urbana, emergiram no continente latino-americano como os principais núcleos de resistência e de enfrentamento às políticas neoliberais. (CLACSO \& CETRI, 2003; TADDEI, 2006; SADER, 2006)

Para Immanuel Wallerstein (2004), o aparecimento destes novos movimentos ecológicos, de mulheres, minorias étnicas, por direitos humanos, povos indígenas e outros assim como o fortalecimento de um novo ciclo de protesto social na região, é fruto não só das profundas e regressivas consequiências das políticas neoliberais adotadas, em diferentes graus, na grande maioria dos países do continente, mas também da desilusão para com o desempenho dos "movimentos anti-sistêmicos clássicos" no poder e com a impossibilidade de cumprimento da promessa de um New Deal Global por parte da nação hegemônica.

Para Taddei \& Seoane (2001) é importante observar a distinta configuração dos movimentos sociais na América Latina e Caribe nos anos noventa em relação às décadas anteriores. Até fins da década de 1980, o conflito assalariado, em particular o industrial, constituía um dos eixos destacados do confronto social na região. Mas o modelo de organização sindical que marcou a atuação da maioria dos movimentos sociais urbanos e rurais, e que cumpria

Revista de Estudos e Pesquisas sobre as Américas V.13 N.2 2019 ISSN: 1984-1639 
um papel importante na articulação político-social das demandas particulares dos sujeitos coletivos, entrou em crise com as transformações estruturais que o neoliberalismo impôs, sobretudo na economia e no mercado de trabalho.

Enquanto as lutas de classe passavam para um segundo plano e os sindicatos recuavam para posições defensivas e reivindicações imediatas, novas demandas surgiam ligadas à idéia dos direitos universais, direitos à educação, saúde, previdência social, habitação, alimentação, identidade cultural... O fim dos anos noventa na América Latina parece ter revertido a "menor conflitividade" registrada no começo desta década. Os sujeitos sociais assumiam nova reconfiguração ao mesmo tempo em que as lutas e resistências multiplicavam e ampliavam-se pelo continente: movimentos dos povos indígenas ${ }^{17}$ e de camponeses ${ }^{18}$ assumiam uma posição de destaque; movimentos de trabalhadores desempregados, sobretudo no Cone Sul, com destaque para os piqueteiros na Argentina; movimentos de operários sob o novo sindicalismo; movimentos das classes médias; movimentos políticos ou ligados à gestão do Estado; movimentos religiosos; estudantil universitário; movimentos feministas, como a marcha mundial das mulheres; movimentos ecológicos, ligados a defesa do meio ambiente, movimento antiglobalização, são alguns exemplos (CLACSO \& CETRI, 2003; HOUTART, 2001; SEOANE \& TADDEI, 2001; TADDEI, 2006).

A adoção do receituário do Consenso de Washington (abertura econômica, privatizações, desregulamentação e flexibilização) e seus resultados de um lado, e a agitação dos movimentos sociais de outro, resultou desde 1998 na ascensão de governos de esquerda e de centro-esquerda: Hugo Chávez na Venezuela, os Kirchner na Argentina, Luiz Inácio Lula da Silva e Dilma Rousseff no Brasil, Michelle Bachellet no Chile, Evo Morales na Bolívia, Rafael Correa no Equador, Tabaré Vazquez e José Mujica no Uruguai, Fernando Lugo no Paraguai. Todavia, Argentina, Uruguai e Brasil converteram-se em claros exemplos de que as políticas econômicas

\footnotetext{
${ }^{17}$ Os exemplos mais emblemáticos na América Latina são o zapatismo no México e Conai no equador. Outros relevantes: no altiplano boliviano; movimentos cocaleiros dos camponeses do sul do Peru e das regiões bolivianas dos Yungas e do Chapare; a Coordenadoria Arauco-Malleco dos povos mapuches do sul chileno; o impulso a partir de 2002 pelos povos originários da América Central contra o Plano Puebla-Panamá.

${ }^{18} \mathrm{O}$ mais importante dos movimentos camponeses da América Latina é sem dúvida o Movimento dos Sem Terra (MST) no Brasil; registram-se também movimentos sem-terra na Bolívia e Paraguai; lutas camponesas no México, Paraguai e América Central, entre outros.
}

Revista de Estudos e Pesquisas sobre as Américas V.13 N.2 2019 ISSN: 1984-1639 
ortodoxas não foram abandonadas, apesar de que as políticas sociais se ampliaram ao longo dos governos chamados progressistas.

Uma análise específica do caso brasileiro, mostra que a expectativa gerada em fins dos anos oitenta diante da possibilidade de um sindicalista chegar ao governo se concretizou. Todavia, como demonstra Sader (2009), foi de certa forma um governo contraditório. No âmbito interno, o governo iniciado com Lula em 2003 e até 2014 havia ampliado a assistência em saúde pública e nas áreas de educação e política cultural, promovido uma queda no déficit habitacional e no desemprego. Ademais, em torno de 53 milhões de brasileiros conseguiram ascender socialmente em termos de renda. No âmbito internacional, o Brasil foi fundamental na extinção da ALCA em 2005, bem como na criação da UNASUL em 2007 e da CELAC em 2012, aumentando com isso a integração regional, e fomentando assim a busca pela soberania latinoamericana. Por outro lado, as políticas econômicas continuaram ortodoxas. O sociólogo Emir Sader assim nos apresenta o "enigma Lula":

O governo Lula pode ser visto como um bom gestor do neoliberalismo, que, além de dar continuidade ao modelo, ainda o complementou com as políticas sociais e a recuperação da legitimidade do Estado, desgastado pelo governo mais ortodoxamente neoliberal de FHC. Também pode ser visto como o governo da política externa independente, que inviabilizou a Alca e privilegiou os processos de integração regional, aliando-se aos governos de Hugo Chávez, Rafael Correa, Evo Morales e outros, entre os quais, o de Cuba. É além disso, aquele que converte o processo de enfraquecimento do Estado, fortalecendo o sistema de educação e de saúde públicas, e expandiu de forma criativa a política cultural. É, sobretudo, o que mais melhorou o nível de vida da massa, em particular dos mais pobres, no país mais desigual do continente, que é o mais desigual do mundo. (...) A lista poderia seguir, sem permitir que se chegue a um resultado claro de superávit ou déficit. A análise política é qualitativa, parte de e orienta-se por critérios estratégicos gerais. Nesse caso, o critério que definimos como fundamental para a América Latina vale também para o Brasil: a prioridade da integração regional em relação aos tratados de livre comércio e a promoção dos direitos econômicos e sociais dos mais pobres, ainda que se trate de um país com altos graus de desigualdade. Diante desse elemento caracterizador da natureza dos governos latino-americanos, o caráter progressista do governo Lula é predominante: ele contribuiu para um mundo multipolar, privilegiando os processos de integração regional e as alianças Sul-Sul; além disso, vem desempenhando um papel importante no Grupo dos 20 (aliança de países subdesenvolvidos) e em outras iniciativas dessa natureza. (SADER, 2009, p.87-89)

Em síntese, é preciso considerar que muitos dos governos eleitos com promessas antineoliberais, entre eles o governo Lula, levaram-nas apenas até certo limite. Avançaram mais no plano da política externa e na adoção de algumas modalidades de políticas sociais, mas no conjunto das ações dos governos progressistas, o neoliberalismo não foi extinto em suas raízes.

Revista de Estudos e Pesquisas sobre as Américas V.13 N.2 2019 ISSN: 1984-1639 
Outros foram um tanto mais longe, imbuídos da proposta de levar adiante o socialismo no século XXI, do qual a Venezuela é o caso mais emblemático. Bolívia e Equador também tencionaram mais a confrontação com o modelo neoliberal, sobretudo com nacionalizações e auditoria da dívida pública. Mas a contra-ofensiva de direita, desatada mais firmemente desde 2007, imprimiu sucessivas derrotas no campo progressista (em Honduras, no Paraguai, na Argentina, Equador...), e demoliu avanços sociais em curtíssimo prazo, por mais tímidos que possam ser considerados por seus críticos de esquerda. Florestan há trinta anos argumentava (em 1988) que "o reformismo dentro da ordem dá todos os seus frutos de uma vez e em seguida salga a terra" (2006, p.246, grifo no original). O Brasil do pós-golpe (2016) é um claro exemplo de como a terra vem sendo salgada em nosso país. Atualmente, mesmo a Venezuela enfrenta enormes dificuldades (sucessivas tentativas de golpes) para manter o curso mais radical. O neoliberalismo se revelou como um câncer não curado, que se manifesta e se reproduz na forma de metástase.

Diante do exposto, quais as alternativas que se nos apresentam? O mesmo Florestan apresentou-nos duas grandes possibilidades de evolução na direção de uma outra história no subcontinente no vir a ser:

Se os setores sociais dominantes e as elites no poder realmente desejam um desenvolvimento gradual e seguro, e se forem capazes de obter apoio popular, suas probabilidades de êxito dependem de um forte nacionalismo revolucionário. Sob as condições econômicas, socioculturais e políticas dos países latino-americanos essa alternativa implica a implantação e o aperfeiçoamento de um novo tipo de capitalismo de Estado, capaz de ajustar a velocidade e intensidade do desenvolvimento econômico e da mudança sociocultural aos requisitos da "revolução dentro da ordem social". A outra resposta alternativa só pode surgir de uma rebelião popular e radical, de orientação socialista. (FERNANDES, 2009, p.39).

\section{Considerações}

Depois de quase meio século de neoliberalismo na América Latina, entende-se que é preciso retomar o debate sobre a luta de classes e os caminhos a serem seguidos. O neoliberalismo tem fortalecido o grande capital financeiro internacional e o capital financeiro latino-americano - historicamente mais associados - e ratificado a reprodução do capitalismo dependente na América Latina. O próprio papel dos Estados latino-americanos tem se modificado

e permitido que o capital financeiro assumisse setores estratégicos antes explorados pelas

Revista de Estudos e Pesquisas sobre as Américas V.13 N.2 2019 ISSN: 1984-1639 
empresas estatais, o que em última instância debilitou a soberania nacional e converteu esses setores em oligopólios e monopólios privados. Assim, o neoliberalismo mostra historicamente que as burguesias latino-americanas - argentina, brasileira, colombiana, peruana, mexicana etc. assumiram um papel menor no desenvolvimento econômico dos Estados nacionais, e ao optarem pelo aprofundamento da associação com o capital financeiro internacional, visaram tão somente a rentabilidade no curto prazo. Ao menor sinal de alarme, uma vez mais, escanrararam o seu lado flibusteiro.

Também do ponto de vista da garantia dos direitos mais elementares da população, não há no horizonte uma burguesia compromissada em cimentar os princípios básicos de um Estado verdadeiramente liberal, o que se verifica quando o ente político prioriza as funções necessárias para a reprodução do capital em detrimento do aprofundamento das políticas públicas e da própria participação democrática. Constata-se, portanto, que o Estado em suas três esferas executivo, legislativo e judiciário - é cada vez mais capturado por uma burguesia associada historicamente, a qual nos anos 1970 ensaiou os primeiros passos do neoliberalismo e o colocou em prática mais generalizada em fins dos anos 1980, com resultados os mais nefastos aqui brevemente sistematizados. Em particular expusemos seus impactos sobre a sorte da classe trabalhadora e dos sem trabalho na região.

Quanto à opção neodesenvolvimentista, cabe salientar seu compromisso para com a reprimarização, e o dado do setor agromineral assumir papel cada vez maior enquanto espaço de valorização do capital, em detrimento do setor industrial. Ademais, os avanços da onda progressista se deram em grande parte junto aos flancos de menor resistência, caso da política social, e isso durante a fase mais favorável do ciclo dos preços de commodities. Mas na fase reversa do ciclo de preços tornou-se mais difícil conciliar os múltiplos interesses contraditórios entre o capital e o trabalho. Nos momentos de maior tensão, as opções de governos progressistas vergaram mais em prol de interesses empresariais do que sociais, contrariando suas bases de apoio. Como dito, o reformismo restrito no âmbito da ordem social vigente deu os seus frutos, mas logo "salgou a terra", e mais recentemente bateu em retirada diante da forte contra-ofensiva contrarrevolucionária.

Finalmente, entende-se que o tempo presente é do domínio e ação de uma burguesia Revista de Estudos e Pesquisas sobre as Américas V.13 N.2 2019 ISSN: 1984-1639 
associada que recrudesce o neoliberalismo na latinoamérica, a qual o leva aos seus extremos em várias partes. A construção de uma alternativa voltada ao resgate de um nacionalismo econômico e político, minimamente inclusivo como nos anos 1940 e 1950, e que teve algum espaço no início do século XXI durante a gestão de governos progressistas, já não faz mais parte do ideário de nossa elite. Já há muito que as burguesias na região abandonaram suas tarefas históricas de levar ao fim e a cabo as revoluções burguesas em atraso, cabendo as classes trabalhadoras levar a diante a revolução socialista. Urge retomar a discussão sobre as possibilidades da construção do socialismo como alternativa para superarmos nossa persistente dependência, como já há muito defendia Florestan Fernandes.

\section{Referências}

AMIN, Samir., HOUTAR, François. (Org.). Mundialização das Resistências: o estado das lutas 2003. São Paulo: Cortez, 2003.

ANDERSON, Perry. "História e lições do neoliberalismo". In: HOUTAR, F. \& POLET, F. (Coord.). O outro Davos: mundialização de resistências e lutas. São Paulo: Cortez, 2002, pp 1630 .

ANTUNES, R. “Os modos de ser da informalidade”. In: ANTUNES, R. Adeus ao trabalho? São Paulo: Cortez Editora, 2016, pp 243-262.

CAMPOS, André, POCHMANN, Márcio, AMORIM, Ricacrdo \& SILVA, Ronnie. (Org.). Atlas da exclusão social no Brasil (vol.2): dinâmica e manifestação territorial. $2^{\circ}$ ed. São Paulo : Cortez, 2004.

CEPAL. "A pobreza aumentou em 2016 na América Latina e alcançou 30,7\% de sua população, Revista de Estudos e Pesquisas sobre as Américas V.13 N.2 2019 ISSN: 1984-1639 
porcentagem que se manterá estável em 2017”. In: https://www.cepal.org/ptbr/comunicados/pobreza-aumentou-2016-america-latina-alcancou-307-sua-populacaoporcentagem-que-se, acesso em 11 de Julho de 2018.

CHANG, H. Chutando a escada: a estratégia do desenvolvimento em perspectiva histórica. São Paulo: Unesp, 2004.

CLACSO; CETRI. “A América Latina”. In: AMIN, S. \& HOUTAR, Fr. (Org.). Mundialização das Resistências: o estado das lutas 2003. São Paulo: Cortez, 2003.

COORDENAÇÃO NACIONAL DA AUDITORIA CIDADÃ DA DÍVIDA. In: https://auditoriacidada.org.br/wp-content/uploads/2018/05/Carta-Aberta-a-Populacao-versaofinal.pdf, acesso em 09 de Julho de 2018.

DUMÉNIL, G; LÉVY, D. "Una teoria marxista del neoliberalismo". In: http://www.rebelion.org/docs/114472.pdf, acesso en 11/07/2018.

FERNANDES, Florestan. "Reflexões finais". In: FERNANDES, Florestan. Pensamento e ação: o PT e os rumos do socialismo. $2^{\circ}$ ed. São Paulo : Globo, 2006, p.242-252.

. Capitalismo dependente e classes sociais na América Latina. $4^{\circ}$ ed., São Paulo: Global, 2009.

G1 Economia. Dívida pública sobe 14,3\% em 2017, para 3,55 trilhões de reais, e bate recorde. In: https://g1.globo.com/economia/noticia/divida-publica-sobe-143-em-2017-para-r-355-trilhoes-ebate-recorde.ghtml, acesso em 09 de Julho de 2018.

HARVEY, David. "Desenvolvimentos geográficos desiguais”. In: HARVEY, David. $O$ neoliberalismo: história e implicações. São Paulo : Loyola, 2008, p.97-129.

Revista de Estudos e Pesquisas sobre as Américas V.13 N.2 2019 ISSN: 1984-1639 
HOBSBAWM, Eric. Era dos extremos: o breve século XX. São Paulo: Companhia das Letras, 2001.

HOUTART, François. "Mundialização das resistências e das lutas contra o neoliberalismo". In: SEOANE, J.; TADDEI, E. Resistências mundiais: de Seattle a Porto Alegre. Petrópolis: Vozes, 2001, pp 89-98.

JORNAL DO BRASIL. In: http://www.jb.com.br/economia/noticias/2018/05/01/informalidadeem-alta-oit-mostra-que-trabalho-informal-supera-60-das-vagas/, acesso em 09 de Julho de 2018.

KATZ, Cláudio. Neoliberalismo, Neodesenvolvimentismo, Socialismo. São Paulo: Expressão Popular, 2016.

LÊNIN, V. I. O imperialismo: fase superior do capitalismo. São Paulo: Global, 1985.

MARINI, Ruy Mauro. Dialética da dependência. In: TRASPADINI, R.; STEDILE, J. P. Rui Mauro Marini. São Paulo: Expressão popular, 2005.

MARX, Karl. O Capital: crítica da economia política. Livro 1, Vol 2. 22a . ed. Rio de Janeiro: Civilização Brasileira, 2008.

OLIVEIRA, Francisco. "Neoliberalismo à brasileira". In: GENTILI, P.; SADER, E. Pósneoliberalismo: as políticas sociais e o Estado democrático. Rio de Janeiro: Paz e Terra, 1995, pp 24-28.

. “A dominação globalizada: estrutura e dinâmica da dominação burguesa no Brasil". In: BASUALDO, Eduardo M. \& ARCEO, Enrique (compil.). Neoliberalismo y sectores dominantes: Tendências globales y experiencias nacionales. $1^{\circ}$ ed. Buenos Aires : CLACSO, 2006, p.265Revista de Estudos e Pesquisas sobre as Américas V.13 N.2 2019 ISSN: 1984-1639 
POCHMANN, Márcio. (Org.). Atlas da exclusão social: os ricos no Brasil. São Paulo: Cortez, 2004.

. Nova classe média? : o trabalho na base da pirâmide social brasileira. São Paulo : Boitempo, 2012.

POCHMANN, Márcio et al. Atlas da exclusão social no Brasil: os ricos no Brasil. São Paulo: Cortez, 2004.

ROSEMANN, M. R. "Neoliberalismo". In: SADER, E.; JINKINGS, I. Enciclopédia contemporânea da América Latina e do Caribe. São Paulo: Boitempo Editorial, 2006, pp 848-854.

SADER, Emir. O anjo torto: esquerda (e direita) no Brasil. São Paulo: Brasiliense, 1995.

. "Esquerda". In: SADER et all. (Coord.). Enciclopédia contemporânea da América Latina e do Caribe. São Paulo/Rio de Janeiro: Boitempo/LPP UERJ, 2006, pp 500-509.

. A vingança da história. São Paulo: Boitempo, 2007.

A nova toupeira: os caminhos da esquerda latino-americana. São Paulo: Boitempo, 2009.

SEOANE, J.; TADDEI, E. Resistências mundiais: de Seattle a Porto Alegre. Petrópolis: Vozes, 2001.

SOARES, Laura Tavares. Ajuste neoliberal e desajuste social na América Latina. Petrópolis: Vozes, 2001.

Revista de Estudos e Pesquisas sobre as Américas V.13 N.2 2019 ISSN: 1984-1639 
VIEIRA, Evaldo. "Estado e políticas social na década de 90”. In: NOGUEIRA, F. M. G. (Org.). Estado e políticas sociais no Brasil. Cascavel: Edunioeste, 2001.

WALLERSTEIN, Immanuel. "Os movimentos: que significa hoje ser um movimento antisistêmico?” In: WALLERSTEIN, I. O declínio do poder americano. Rio de Janeiro: Contraponto, 2004, pp 21-36.

\title{
Considerações acerca do neoliberalismo e do progressismo na América Latina
}

\begin{abstract}
Resumo
O presente artigo visa contribuir com a avaliação do neoliberalismo e do progressismo na América Latina, desde suas origens até o momento atual, bem como avaliar alternativas que se lhes apresentam. Para o pensamento crítico são inegáveis os efeitos deletérios do neoliberalismo em nossa região. Para realizar o projeto neoliberal, seus artífices propuseram um conjunto articulado de reformas estruturais, dentre as quais se destacaram uma forte economia de mercado, a retirada do Estado da esfera econômica e social por meio da diminuição do gasto público, a redução de barreiras para a livre mobilidade de capitais, bem como o estabelecimento de um mercado de trabalho cada vez mais flexível. É o que temos em vista na análise do neoliberalismo latino-americano e a ratificação do capitalismo dependente. Certamente mais polêmicos foram os acertos e os erros das experiências progressistas para superá-lo, assim como o são os desafios que temos pela frente. É o que temos em vista ao analisarmos a esquerda latinoamericana frente ao avanço neoliberal como um precedente rico em lições para o século XXI.
\end{abstract}

Palavras-chave: América Latina; neoliberalismo; progressismo; esquerda latino-americana.

\section{Considerations regarding neoliberalism and progressivism in Latin America}

\begin{abstract}
This article aims to contribute to the evaluation of neoliberalism and progressivism in Latin America, since its origins until present time, and to evaluate the possible alternatives to it today. Critical authors state that the deleterious effects of neoliberalism in our region are undeniable. In order to carry out the neoliberal project, its architects proposed an articulated set of structural reforms, among them a strong market economy, the withdrawal of the State from the economic and social sphere through the reduction of public spending, the reduction of barriers to free mobility of capital and the establishment of an increasingly flexible labor market. This is what we intend to do in this analysis of Latin American neoliberalism and the ratification of dependent capitalism. Certainly more controversial were the gains and errors of the progressive experiences to overcome it and are the challenges that we face from now on. This is what we aim when we analyse the left wing in Latin America ahead of the neoliberal advance as a precedent full of lessons for the 21 st century.
\end{abstract}

Keywords: Latin America; neoliberalism; progressivism; Latin American left wing.

\section{Consideraciones acerca del neoliberalismo y del progresismo en América Latina}

\section{Resumen}

Revista de Estudos e Pesquisas sobre as Américas V.13 N.2 2019 ISSN: 1984-1639 
El artículo busca contribuir con la evaluación del neoliberalismo y del progresismo en América Latina, desde sus orígenes hasta la actualidad, así como evaluar las alternativas presentes. Para el pensamiento crítico son innegables los efectos deletéreos del neoliberalismo en nuestra región. Para la realización del proyecto neoliberal, sus artífices propusieron un conjunto articulado de reformas estructurales, dentro de las cuales se destacaron una fuerte economía de mercado, la quitación del Estado en el ámbito económico y social por medio de la disminución del gasto público, la reducción de las barreras a la libre movilidad de los capitales, así como el establecimiento de un mercado de trabajo cada vez más flexible. Esto es lo que tenemos en cuenta en el análisis del neoliberalismo latinoamericano y la ratificación del capitalismo dependiente. Ciertamente más polémicos fueron los aciertos y errores de las experiencias progresistas para superarlo, así como lo son los desafíos que tenemos por delante. Es lo que tenemos en vista al analizar la izquierda latinoamericana frente al avance neoliberal como un precedente rico en lecciones para el siglo XXI.

Palabras clave: América Latina; neoliberalismo; progresismo; izquierda latinoamericana.

Revista de Estudos e Pesquisas sobre as Américas V.13 N.2 2019 ISSN: 1984-1639 